Direct acoustic connection to the wing surface could be used if preferred".

There is reason for believing that any attempt to achieve man-powered flight by flapping wings must fail. The mechanical limitations imposed by the physiology of the living animal, such as blood circulation and growth, permit locomotion only by the use of oscillatory systems with their inherent problems of inertial forces. Such forces may well set a limit to the size of birds. Manmade devices using rotary motion are not limited by such alternating stresses.

It is true that, as the author says, there is much yet to be learnt about natural flight, but it will not be learnt by this approach.

R. H. J. BRown

\section{Thinking Computers}

Problems of Heuristics. Edited by V. N. Pushkin. Translated from Russian. Pp. $v i+202$. (Israel Program for Scientific Information: Jerusalem; John Wiley: Chichester, March 1973.) £8.45.

THIs book is a translation-a very competent one-of a collection of papers published by the Institute of Psychology of the Academy of Pedagogical Sciences of the USSR in 1969. It gives one a fascinating glimpse into the current thinking of Russian psychologists about human thought and the problems of describing it in programmatic terms. Apparently there is as much lively discussion in the USSR as in the West of the possibilities and limitations of computer models of psychological processes; whatever the future of artificial intelligence and heuristic programming, it is good to see the issues discussed in such a thoroughgoing fashion.

The authors represent a wide variety of disciplines, including psychology, logic, pure mathematics and engineering. Their interests are reflected in the structure of the book, which is divided into four parts. Parts 1 and 2, entitled "Theoretical Problems and Heuristics" and "Experimental Studies and Heuristic Processes" respectively, are intellectually dominated by the editor's own contributions. He sees clearly the need to study human performance in order to construct effective algorithms for automatic process control and problem solving, and draws attention to the serious deficiencies of "stimulus-response" automata as models of human problem solving. What we need, he suggests, is a theory of "heuristic automata" which could model the elements of a given problem, construct systems from these elements and use the systems for solving the problem. Unfortunately there is no general theory of such automata at the present time.

The other two parts of the book are entitled "Programming and Components of Human Thought" and "Investigation of Reflexive Processes". The latter is the shortest section and the most idiosyncratic; it deals with "devices which optimise their performance in response to human counteraction", and it is not clear that they have very much to tell us about human thought. But the main body of the book, represented by parts 2 and 3 , is a mine of case studies of human beings attempting to solve simple (and not so simple) intellectual problems. There is a thoroughly professional chapter on the perception and recollection of board positions in chess, this study being backed up by observing the eye movements which accompany the examination of a board position in the process of attempting to memorise it or to solve a chess problem. There is a comparison between the performance of humans and computers in solving various kinds of rearrangement puzzles and a very long chapter on the famous problem of the fly which travels to and fro between two cyclists riding towards each other-though perhaps it generates more amusement than psychological insight. In part 3 the most interesting paper is one on the automatic design of pipelines, an exercise in cooperation between human designers and computing machines. It seems to be inspired by a good sense of the proper place for computers in human society.

\section{H. C. Longuet-Higoins}

\section{Medical Thoughts}

Medicine and Society. By H. Miller. Pp. 87. (Oxford University: London, August 1973.) £2.25 library edition; 80p paper.

THIS is an excellent book that ought to be read by anyone with the slightest interest in medicine and medical services. In eighty pages Dr Miller gallops through (inter alia) drug development, operation of the National Health Service, staffing of hospitals, general practice, population screening, education, dentistry, genetics, abortion, euthanasia, transplants, contraception and the medical needs of the third world. He says something interesting and provocative about them all, and doesn't waste a word.

The Medical Research Council and molecular biology are rapidly dispatched in "it is still difficult to escape the impression that the collection of Nobel prizes and the headlong pursuit of the almost metaphysical harvest of molecular biology has taken precedence over the exploitation of science in the service of medicine and man". He clearly dislikes any thought that euthanasia might be available through the medical profession: "It might be more appropriate for an enthusiastic prelate to conduct the patient to the Elysian fields".

This is just the book for a ninetyminute train journey.

David Davies

\section{Rationalizing Water}

Scientific Allocation of Water Resources : Water Resources Development and Utilization-A Rational Approach. By Nathan Buras. Pp. 208. (American Elsevier: New York ; Elsevier : Amsterdam, 1972.) Dfl.46; $\$ 14.50$.

THE last decade has seen both a much greater awareness of the many severe and growing complications (technical, legal and social) in water resources studies and the development of powerful systems engineering techniques. The techniques, however, cannot yet cope fully with all the complexities of the overall water resources problem. Either the problem has to be simplified in certain aspects or the techniques are applied to particular components of the overall problem.

In the latter category, Buras has made notable contributions to the development and application of systems techniques in water resources engineering. His book shows succinctly (in 200 pages) his authoritative grasp of the subject and is to be welcomed for bringing together material dispersed over a plethora of journals and proceedings.

The preface and introduction give respectively lucid surveys of the book itself and of the historical background of water resource development from Biblical times onwards. The overlap of water resources engineering with many related disciplines in the pure and applied sciences and in the social sciences is well summarized in the introduction.

Chapter 2 sets out the philosophy of the systems approach to water resources studies, without obscuring that philosophy with mathematics. Summaries of applications of the approach in California, the Indus Valley and Israel are presented. Wisely, Buras stresses that the application of systems engineering to water resources problems is only in its initial exploratory stage.

After distinguishing between develop. ment problems, design problems and operational problems in chapter 3 , he gives a full account of those probabilistic methods applied in water resources studies, with the minimum of mathematical obscuration, in chapter 4 .

The optimization techniques widely used in water resources problems, and to which Buras has himself made many contributions, are set out in chapters 5 , 6 and 7 . Linear programming, with specific examples to leaven the basic material, is adequately covered in chapter 5. The main value of the whole book, however, may well be the thorough treatment given to dynamic programming methods, both as a way of approach and in their application, in chapters 6 and 7. These chapters seem to me to be the outstanding feature of the book, and will provide a sound insight to this complex subject. A brief 